
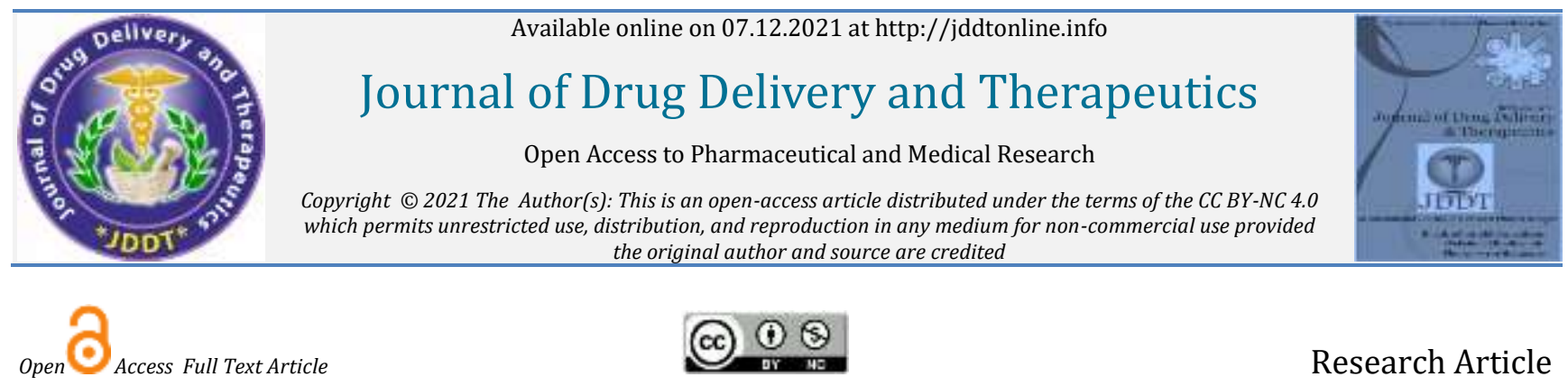

Research Article

\title{
Formulations of sustained release matrix tablets of Furosemide using natural and synthetic polymers
}

\author{
Shivani Soni, Vivek Jain, Sunil Kumar Jain, Pushpendra Kumar Khangar* \\ Adina Institute of Pharmaceutical Science, NH86A, Lahdara, Sagar, MP 470001
}

\section{Article Info:}

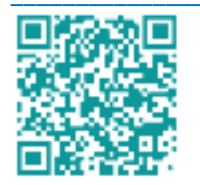

\section{Article History:}

Received 09 October 2021

Reviewed 18 November 2021

Accepted 27 November 2021

Published 07 December 2021

\section{Cite this article as:}

Soni S, Jain V, Jain SK, Khangar PK, Formulations of sustained release matrix tablets of Furosemide using natural and synthetic polymers, Journal of Drug Delivery and Therapeutics. 2021;

11(5):105-109

DOI: http://dx.doi.org/10.22270/jddt.v11i5.5122

\section{Abstract}

The primary benefit of a sustained release dosage form compared to a conventional dosage form, is the consistent drug plasma concentration and consequently uniform therapeutic effect. Matrix system are preferential because of their ease, patient compliance etc, than traditional drug delivery which have several drawbacks like reiterated administration, variation in blood concentration level etc. The aim of the present research study was to develop and evaluate sustained release matrix tablets of furosemide using direct compression method using natural gummy and waxy materials (Xanthan gum, bees wax) and synthetic polymers (HPMC $\mathrm{K}_{4} \mathrm{M}$ ). The matrix tablet formulations were prepared by using different drug: polymer ratios $(1: 1,1: 2$ and 1:3). All formulations were assessed using micromeritics studies of powder blend and diverse physicochemical tests. All the physicochemical characters of the formulated tablets were within acceptable limits. The release pattern of the drug was viewed over a period of 12 hours and determined the amount of drug by the UV-Visible spectroscopic method. Dissolution data demonstrated that the formulated tablets with Xanthan gum and hydroxyl propyl methylcellulose (HPMC) provided sustained release of the drug up to $12 \mathrm{hrs}$. Therefore inexpensively it may be appropriate for the pharmaceutical industries to employ this kind of simple technologies for the expansion of advanced formulations. Hence, we conclude that the purpose of this study was to formulate a sustained release matrix tablet of furosemide using diverse polymers and their dissimilar proportions have been attained.

Keywords: Furosemide, Direct compression, Natural, Synthetic polymers, Sustained release tablets.

*Address for Correspondence: Pushpendra Kumar Khangar, Adina Institute of Pharmaceutical Science, NH86A, Lahdara, Sagar, MP 470001

\section{INTRODUCTION}

Oral administration of drugs is generally preferred, especially over parenteral administration. Oral products are produced in a extra cost-effective way in contrast with parenteral products and report for about $60 \%$ of all prescription products universal ${ }^{1}$. Sustained-release oral drug products are intended to gradually release the active ingredient above an extensive time following administration and present noteworthy benefits above conventional orally administered products, counting decrease side effects, enhance safety and patient compliance by reducing the incidence of dosing and reduced drug plasma-concentration variations ${ }^{2}$, 3. Matrix formulations of hydrophilic and/or hydrophobic polymers have been employed to manage the release of drugs 4,5 and can be created using conventional processing equipment. Formulation based on a hydrophilic matrix was selected, as it is recognized to provide robust formulae that can be manufactured by standard tabletting technology. In accumulation, it is probable to manufacture such formulations without using organic solvents; environmental dangers connected with such solvents cause immense concern and they often yield trace remains in finished products. Sustain release dosage forms are easily manufactured using matrix system of different control release excipients including hydrophilic polymers such as HPMC, insoluble gum and waxes are used (for extending the release of drugs) as matrix-forming components in solid dosage forms. HPMC has been employed extensively as hydrophilic matrix former in oral controlled-release dosage forms for different drugs. Its reputation can be accredited to the polymer's non-toxic nature, small persuade of processing variables on drug release, alleviate of compression, and its capability to accommodate elevated levels of drug loading, its aptitude to swell upon jellification once in contact with water ${ }^{6-8}$. Waxes have an advantage over other materials because it is chemically inert against other materials. The waxy and hydrophobic substances are simply erodible and well control the release pattern of the drug through the mechanism of erosion and pore diffusion. A lot of researchers employed carnauba wax as deterrent material in dissimilar sustained released formulations 9 , 10. Xanthan gum is an elevated molecular weight extracellular polysaccharide, created on commercial scale by the viscous fermentation of gram negative bacterium Xanthomonas campesteris. The molecule consists of a backbone equal to that of cellulose, with side chains connected to interchange glucose residues. It is a hydrophilic polymer, which until lately had been limited for employ in thickening, suspending and emulsifying 
water based systems ${ }^{11}$. The hydrophilic polymers expand a viscous gelatinous surface barrier after hydration; this gelatinous barrier manages the drug release from matrix systems ${ }^{12}$. Furosemide (4-chloro-2-furfurylamino- 5sulphamoyl benzoic acid) is a drug with a diuretic action which proceeds at the renal level on the ascending limb of the loop of Henle. The half life of furosemide is upto 100 minutes, dose ranges $20-40 \mathrm{mg}$ and bioavailability is $43-$ $69 \%$. Furosemide is used in management of hypertension and also as diuretics. Sustained-release tablets of furosemide give steady plasma concentration with fewer recurrent administrations and also reduce the side effects to a few extents. This could expand its secure administration and improve patient compliance ${ }^{13}$. Therefore, the aim of present study was to assess the strength of xanthan gum, beeswax and HPMC K4M on sustaining the release of furosemide from the matrix system. Furthermore, the influence of dissimilar polymers nature and concentration was evaluated on the release pattern of furosemide.

\section{MATERIALS AND METHODS}

\section{Materials}

Furosemide was obtained as a gift sample from Wokhardth Pharma Pvt. Ltd Aurangabad. Suitable grade of HPMC K4M was obtained from Colorcon Asia Pvt Ltd Goa. Xanthan gum was obtained from Bangalore Fine Chem, Bangalore. Lactose DC kindly provided from Merck (Germany). Bees wax was procured from Sigma-Aldrich (USA). Talc, MCC, PVP K-30 and magnesium stearate was purchased from Loba chem Pvt. Ltd., Mumbai (India). All other solvents and reagents were purchased from Merck (Germany) and were of analytical grade.

\section{Methods}

\section{Preformulation studies}

Physical characteristics: By visual examination, the drug was recognized for physical characters like colour, texture, odour etc.

\section{Solubility}

Solubility of the drug was indomitable by taking some quantity of drug (about 1-2 mg) in the test tube separately and added the $5 \mathrm{ml}$ of the solvent (water, ethanol, methanol, $0.1 \mathrm{~N} \mathrm{HCL}, 0.1 \mathrm{~N} \mathrm{NaOH}$, chloroform and $7.4 \mathrm{pH}$ buffer) Shake vigorously and kept for some time. Note the solubility of the drug in various solvents (at RT).

\section{Melting point determination}

Melting point of drug was indomitable by Open capillary method.

\section{Determination of $\lambda_{\text {max }}$ of furosemide}

Accurately weighed $10 \mathrm{mg}$ of drug was dissolved in $10 \mathrm{ml}$ of phosphate buffer pH 5.8 solutions in $10 \mathrm{ml}$ of volumetric flask. The resulted solution $1000 \mu \mathrm{g} / \mathrm{ml}$ and from this solution $1 \mathrm{ml}$ pipette out and transfer into $10 \mathrm{ml}$ volumetric flask and volume make up with phosphate buffer $\mathrm{pH} 5.8$ solution. Prepare suitable dilution to make it to a concentration range of $2-10 \mu \mathrm{g} / \mathrm{ml}$. The spectrum of this solution was run in $400-800 \mathrm{~nm}$ range in U.V. spectrophotometer (ShimadzuUV-1600, Japan). A graph of concentration Vs absorbance was plotted.

\section{FTIR spectroscopy}

Identification of furosemide was done by FTIR spectroscopy with respect to marker compound. Furosemide was obtained as white to brownish powder. It was identified from the result of IR spectrum as per specification. FTIR spectra recorded on $\mathrm{KBr}$ disk method using Brukers Alpha Spectrophotometer with IR solution software. Sample powder was thoroughly mixed by triturating with $\mathrm{KBr}$ in a glass mortar with pestle and compressed into disks in a hydraulic press. FTIR spectra of all the samples were recorded over a spectral region from 4700 to $400 \mathrm{~cm}-1$ using 20 scans with $4 \mathrm{~cm}-1$ resolution.

\section{Method for preparation of sustained release furosemide matrix tablets}

Sustained release tablets of furosemide were prepared using natural gummy and waxy materials (Xanthan gum, bees wax) and synthetic polymers (HPMC K4M). This controlled release natural and synthetic materials were employed in different ratios with the drug i.e. 1:1, 1:2 and 1:3, while the amount of the furosemide was kept constant as $20 \mathrm{mg}$. Lactose DC, talc and magnesium stearate were employed as filler, lubricant and anti-adherent respectively. The composition of different formulations of sustained release matrix tablets is presented in Table 1. All the ingredients were reduced and uniform their particle size by passing through \# 100 sieves size then accurately weighed individually and mixed in a mortar with pestle using geometrical dilution method and then directly compressed into tablets using a single punch rotary tablet machine using $10 \mathrm{~mm}$ flat punches.

Table 1: Composition of SR matrix tablet of furosemide

\begin{tabular}{|c|c|c|c|c|c|c|c|c|c|}
\hline Ingredients mg/tablet & F1 & F2 & F3 & F4 & F5 & F6 & F7 & F8 & F9 \\
\hline Furosemide & 20 & 20 & 20 & 20 & 20 & 20 & 20 & 20 & 20 \\
\hline Xanthan gum & 20 & 40 & 60 & - & - & - & - & - & - \\
\hline Bees Wax & - & - & - & 20 & 40 & 60 & - & - & - \\
\hline HPMC K4M & - & - & - & - & - & - & 20 & 40 & 60 \\
\hline PVP K 30 & 3.0 & 3.0 & 3.0 & 3.0 & 3.0 & 3.0 & 3.0 & 3.0 & 3.0 \\
\hline $\begin{array}{c}\text { Microcrystalline } \\
\text { cellulose }\end{array}$ & 93 & 73 & 53 & 93 & 73 & 53 & 93 & 73 & 53 \\
\hline Talc & 2.0 & 2.0 & 2.0 & 2.0 & 2.0 & 2.0 & 2.0 & 2.0 & 2.0 \\
\hline Magnesium stearate & 2.0 & 2.0 & 2.0 & 2.0 & 2.0 & 2.0 & 2.0 & 2.0 & 2.0 \\
\hline Lactose & 10 & 10 & 10 & 10 & 10 & 10 & 10 & 10 & 10 \\
\hline
\end{tabular}




\section{Evaluation of furosemide SR matrix tablets}

\section{Pre-compression parameters}

\section{Angle of repose}

The angle of repose of blends was established by the funnel method. The exactly weighed blend was taken in the funnel. The height of the funnel was adjusted in such a way that the tip of the funnel just touched the apex of the heap of the blend. The blend was allowed to flow from the funnel on the surface. The diameter and height of the heap formed from the blend were measured. The angle of repose was calculated using the following formula ${ }^{14}$.

\section{$\operatorname{Tan} \theta=h / r$}

Where, " $h$ " is the height of the heap and " $r$ " is the radius of the heap of granules.

\section{Bulk density (BD)}

An exactly weighed powder blend from every formula was lightly shaken to break any agglomerates formed and it was introduced in to a measuring cylinder. The volume occupied by the powder was measured which gave bulk volume. The furosemide of powder blends was determined using the following formula 15 .

Bulk density $=$ Total weight of powder $/$ Total volume of powder

\section{Tapped bulk density (TBD)}

An exactly weighed powder blend from every formula was lightly shaken to break any agglomerates formed and it was introduced into a measuring cylinder. The measuring cylinder was tapped until no further change in volume was noted which gave the tapped volume. The TBD of powder blends was determined using the following formula ${ }^{16}$. TBD $=$ Total weight of powder $/$ Total volume of tapped
powder

\section{Carr's compressibility index}

The Carr's compressibility index was calculated from bulk density (BD) and tapped density of the blend. A quantity of $2 \mathrm{gm}$ of blend from each formulation, filled into a $10 \mathrm{ml}$ of measuring cylinder. Initial bulk volume was measured, and cylinder was allowed to tap from the height of $2.5 \mathrm{~cm}$. The tapped frequency was $25 \pm 2 /$ min to measure the tapped volume of the blend. The BD and tapped density were calculated by using the bulk volume and tapped volume. Carr's compressibility index was calculated using the following formula ${ }^{17,18}$.

Carr's compressibility index $(\%)=[($ Tapped density-Bulk density) $\times 100] /$ Tapped density

\section{Hausner's Ratio}

It is the measurement of frictional resistance of the drug. The ideal range should be $1.2-1.5$, it was determined by the ratio of tapped density and bulk density.

$$
\text { HR = Tapped Density/ Bulk Density }
$$

\section{Post-compression parameters}

\section{Shape of tablet}

Directly compressed tablets were inspected under the magnified lens for the shape.

\section{Thickness}

20 tablets from the envoy sample were arbitrarily taken and individual tablet thickness was measured by using digital vernier caliper ${ }^{19}$.

\section{Hardness}

Tablet hardness was calculated by using Monsanto hardness tester. From each batch 6 tablets were calculated for the hardness and average of six values was noted along with standard deviations.

\section{Friability test}

From every batch, 10 tablets were exactly weighed and placed in the friability test apparatus (Roche friabilator). Apparatus was operated at $25 \mathrm{rpm}$ for 4 minutes and tablets were observed while rotating. The tablets were then taken after 100 rotations, de dusted and reweighed. The friability was calculated as the percentage weight loss. \% friability was calculated as follows

$$
\% \text { Friability }=(\mathrm{W} 1-\mathrm{W} 2) \times 100 / \mathrm{W} 1
$$

Where $\mathrm{W} 1=$ Initial weight of the 10 tablets, $\mathrm{W} 2=$ Final weight of the 10 tablets after testing.

Friability values below $0.5-1 \%$ are generally acceptable . $^{8}$

\section{Weight variation test}

To study weight variation individual weights (WI) of 20 tablets from every formulation were noted using electronic balance. Their average weight (WA) was calculated. \% weight variation was calculated. Average weights of the tablets along with standard deviation values were calculated.

\section{Drug content}

The test is obligatory for tablets with $10 \mathrm{mg}$ or less weight of active ingredient. 10 randomly selected tablets from every formulation (F1 to F9) were finely powdered and drug equivalent to $10 \mathrm{mg}$ of drug dissolved in $10 \mathrm{ml}$ phosphate buffer $\mathrm{pH} 5.8$ sonicate it for 20 minutes, till the entire drug leached out from complex, then the solution was filtered through whatman filter paper No. 41. From this solution take $1 \mathrm{ml}$ and diluted up to $100 \mathrm{ml}$ with phosphate buffer $\mathrm{pH}$ 5.8 and the drug content was determined spectrophotometrically at $272 \mathrm{~nm}$.

\section{Dissolution rate studies}

In vitro drug release of the sample was done using USP-type II dissolution apparatus (Paddle type). The dissolution medium, $900 \mathrm{ml}$ Phosphate buffer $\mathrm{pH} 5.8$ was set into the dissolution flask maintaining the temperature of $37 \pm 0.5^{\circ} \mathrm{C}$ and $\mathrm{rpm}$ of 50 . One furosemide tablet was set in every container of dissolution apparatus. The mechanical assembly was permitted to keep running for 12hours. Sample measuring $5 \mathrm{ml}$ were pulled back after time intervals up to 12 hours using $5 \mathrm{ml}$ pipette. The new disintegration medium $\left(37^{\circ} \mathrm{C}\right)$ was supplanted each time with a similar amount of the sample and takes the absorbance at $272 \mathrm{~nm}$ using spectroscopy.

\section{RESULTS AND DISCUSSION}

Solubility of furosemide was slightly soluble in water, chloroform, ether; soluble in acetone, methanol, dilute $\mathrm{NaOH}$ DMF; less soluble in ethanol. The melting point of furosemide was $204-206^{\circ} \mathrm{C}$. $\lambda_{\max }$ of furosemide was establish to be 272 $\mathrm{nm}$ by using U.V. spectrophotometer (UV-1600 Shimadzu, Japan) in linearity range $2-10 \mu \mathrm{g} / \mathrm{ml}$. Identification of furosemide was done by FTIR spectroscopy with respect to marker compound. It was identified from the consequence of 
IR spectrum as per specification Fig.1. Tablet powder blend was subjected to different pre-compression parameters Table 2. The angle of repose values shows that the powder blend has good flow properties. The bulk density of all the formulations was established to be in the range of $0.47 \pm$ 0.11 to $0.54 \pm 0.09(\mathrm{gm} / \mathrm{ml})$ showing that the powder has good flow properties. The tapped density of all the formulations was establish to be in the range of $0.56 \pm 0.05$ to $0.65 \pm 0.06$ demonstrating the powder has good flow properties. The compressibility index of all the formulations was establish to be ranging between $16.4 \pm 0.13$ to $21.5 \pm$ 0.03 which demonstrate that the powder has good flow properties. All the formulations have shown the Hauser's ratio ranging between $1.15 \pm 0.13$ to $1.26 \pm 0.13$ indicating the powder has good flow properties. The consequences of postcompression parameters such as the uniformity of weight, hardness, thickness, friability and disintegration time of the tablets are given in Table 3. All the tablets of dissimilar batches complied with the official requirements of uniformity of weight. The hardness of the tablets ranged from $9.1 \pm 0.11$ to $9.5 \pm 010 \mathrm{~kg} / \mathrm{cm}^{2}$ and the friability values were less than $0.5 \%$ indicating that the matrix tablets were compact and hard. The thickness of the tablets ranged from
$4.21 \pm 0.35$ to $6.64 \pm 0.03 \mathrm{~mm}$. All the formulations satisfied the content of the drug as they contained $95.9 \pm 103.1 \pm 2.8$ $\%$ of furosemide and good uniformity in drug content was observed. Thus all the physical attributes of the prepared tablets were found be practically within control. The tablets were evaluated for in vitro dissolution studies in phosphate buffer $\mathrm{pH} 5.8$ for 12 hrs. The results of the optimized formulation F-9 showed maximum drug release i.e. $89.47 \pm$ $0.24 \%$ at the end of $12 \mathrm{hrs}$. The results of release studies of formulations F9 was shown in Table 4.

\section{CONCLUSION}

Dissolution studies consequences indicated that the furosemide release from formulated tablets was not usually comparable and steady for all formulations containing dissimilar control releasing materials. In general reduce in furosemide release rate with respect to decrease in ratio of HPMC in formulations. The initial burst of matrix tablets had been seized using high viscosity grades polymers. Furthermore, xanthan gum and HPMC polymers demonstrated constant and controlled release rate and no modification were observed up to $12 \mathrm{hrs}$. Direct compression uses the smallest amount of machinery and man power.

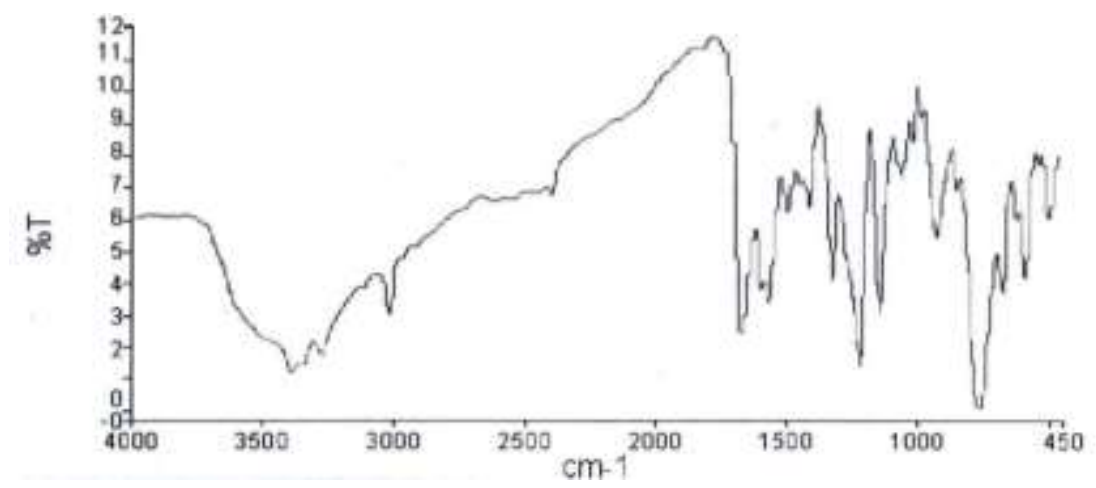

Figure 1 FT-IR spectrum of pure drug furosemide

Table 2: Result of pre-compression properties of furosemide matrix tablets

\begin{tabular}{|c|l|l|l|l|l|}
\hline \multirow{2}{*}{ F. Code } & \multicolumn{5}{|c|}{ Parameter } \\
\cline { 2 - 6 } & \multicolumn{1}{|c|}{ BD (gm/ml) } & \multicolumn{1}{|c|}{ TD } \\
& & \multicolumn{1}{|c|}{ Carr's index (\%) } & \multicolumn{1}{c|}{ Hauser's ratio } & Angle of Repose \\
\hline F-1 & $0.51 \pm 0.06$ & $0.64 \pm 0.03$ & $20.1 \pm 0.08$ & $1.23 \pm 0.10$ & $30.3 \pm 0.09$ \\
\hline F-2 & $0.50 \pm 0.02$ & $0.62 \pm 0.04$ & $18.3 \pm 0.04$ & $1.20 \pm 0.12$ & $29.6 \pm 0.17$ \\
\hline F-3 & $0.52 \pm 0.06$ & $0.64 \pm 0.07$ & $21.5 \pm 0.03$ & $1.23 \pm 0.07$ & $31.4 \pm 0.08$ \\
\hline F-4 & $0.48 \pm 0.04$ & $0.57 \pm 0.03$ & $17.4 \pm 0.07$ & $1.15 \pm 0.04$ & $26.2 \pm 0.12$ \\
\hline F-5 & $0.51 \pm 0.05$ & $0.63 \pm 0.06$ & $20.4 \pm 0.12$ & $1.23 \pm 0.07$ & $33.4 \pm 0.07$ \\
\hline F-6 & $0.54 \pm 0.09$ & $0.65 \pm 0.06$ & $21.4 \pm 0.06$ & $1.26 \pm 0.13$ & $40.1 \pm 0.12$ \\
\hline F-7 & $0.47 \pm 0.11$ & $0.56 \pm 0.05$ & $16.4 \pm 0.13$ & $1.15 \pm 0.13$ & $29.5 \pm 0.11$ \\
\hline F-8 & $0.51 \pm 0.08$ & $0.64 \pm 0.03$ & $21.4 \pm 0.14$ & $1.23 \pm 0.06$ & $34.0 \pm 0.05$ \\
\hline F-9 & $0.50 \pm 0.09$ & $0.62 \pm 0.02$ & $21.3 \pm 0.07$ & $1.26 \pm 0.07$ & $40.4 \pm 0.03$ \\
\hline
\end{tabular}


Table 3: Results of post compression properties of IB matrix tablets

\begin{tabular}{|c|c|c|c|c|c|c|}
\hline \multirow{2}{*}{$\begin{array}{c}\text { Batch } \\
\text { code }\end{array}$} & $\begin{array}{c}\text { Thickness } \\
\mathbf{( m m )}\end{array}$ & $\begin{array}{c}\text { Diameter } \\
\mathbf{( m m )}\end{array}$ & $\begin{array}{c}\text { Hardness } \\
\mathbf{( K g )}\end{array}$ & $\begin{array}{c}\text { Weight } \\
\text { variation }\end{array}$ & $\begin{array}{c}\text { Friability } \\
\mathbf{( \% )}\end{array}$ & $\begin{array}{c}\text { Assay } \\
\mathbf{( \% )}\end{array}$ \\
\hline F-1 & $3.38 \pm 0.09$ & $6.21 \pm 0.71$ & $4.83 \pm 0.41$ & $305.8 \pm 1.10$ & $0.29 \pm 0.04$ & $102.5 \pm 2.6$ \\
\hline F-2 & $3.61 \pm 0.05$ & $6.38 \pm 0.83$ & $4.64 \pm 0.53$ & $406.3 \pm 0.85$ & $0.17 \pm 0.02$ & $95.9 \pm 2.8$ \\
\hline F-3 & $3.85 \pm 0.03$ & $6.44 \pm 0.54$ & $4.33 \pm 0.32$ & $505.8 \pm 0.98$ & $0.10 \pm 0.08$ & $103.1 \pm 2.8$ \\
\hline F-4 & $3.32 \pm 0.01$ & $6.05 \pm 0.21$ & $4.21 \pm 0.35$ & $305.5 \pm 0.89$ & $0.25 \pm 0.25$ & $100.1 \pm 1.5$ \\
\hline F-5 & $3.51 \pm 0.07$ & $6.24 \pm 0.56$ & $4.23 \pm 0.89$ & $405.8 \pm 0.54$ & $0.03 \pm 0.09$ & $101.1 \pm 3.8$ \\
\hline F-6 & $3.79 \pm 0.06$ & $6.30 \pm 0.35$ & $4.38 \pm 0.25$ & $505.7 \pm 0.96$ & $0.04 \pm 0.07$ & $97.5 \pm 1.8$ \\
\hline F-7 & $3.24 \pm 0.17$ & $6.92 \pm 0.35$ & $6.12 \pm 0.04$ & $306.5 \pm 0.89$ & $0.32 \pm 0.05$ & $99.5 \pm 3.6$ \\
\hline F-8 & $3.51 \pm 0.05$ & $6.11 \pm 0.35$ & $6.31 \pm 0.05$ & $405.4 \pm 0.97$ & $0.41 \pm 0.05$ & $98.9 \pm 2.5$ \\
\hline F-9 & $3.62 \pm 0.03$ & $6.27 \pm 0.24$ & $6.64 \pm 0.03$ & $506.2 \pm 0.87$ & $0.49 \pm 0.11$ & $102.0 \pm 2.8$ \\
\hline
\end{tabular}

Table 4: In-vitro drug release data for optimized formulation F-9

\begin{tabular}{|c|c|c|}
\hline S. NO. & Time (Hrs) & F-9 (\%) \\
\hline 1 & 1 & $18.54 \pm 0.12$ \\
\hline 2 & 2 & $32.61 \pm 0.14$ \\
\hline 3 & 4 & $46.82 \pm 0.21$ \\
\hline 4 & 6 & $54.83 \pm 0.17$ \\
\hline 5 & 8 & $62.96 \pm 0.22$ \\
\hline 6 & 12 & $89.47 \pm 0.24$ \\
\hline
\end{tabular}

\section{REFERENCES}

1. Advanced oral and parenteral drug delivery technologies: Players, products \& prospects to 2015. Dublin: Espicom Business Intelligence Ltd, 2011.

2. Charman SA, Charman W. Oral modified-release delivery systems. In: Rathbone, M.J.; Hadgraft, J.; Roberts, M.S. (Eds.). Modified release drug delivery technology. New York: Marcel Dekker, 2002. chap. 1. https://doi.org/10.1201/9780203910337.pt1

3. Moodley K, PillaryV, ChoonaraYE, Toit LC, Ndesendo VMK, Kumar, $\mathrm{P}$ et al., Oral drug delivery systems comprising altered geometric configurations for controlled drug delivery. Int J Mol Sci 2012; 13:18-43. https://doi.org/10.3390/ijms13010018

4. Malmsten M. Surfactants and polymers in drug delivery. Stockholm: Marcel Dekker, 2002; 335. https://doi.org/10.1201/9780824743758

5. Qiu LY, Bae, YH. Polymer architecture and drug delivery. Pharmac Res 2006; 23(1):1-30. https://doi.org/10.1007/s11095-0059046-2

6. Gil EC, Colarte AI, Bataille B, Pedraz JL, Rodrigez F, Heinamaki J. Development and optimization of a novel sustained release dextran tablet formulation for propranolol hydrochloride. Int J Pharm 2006; 317(1):32-39. https://doi.org/10.1016/j.ijpharm.2006.02.049

7. Lopez CM, Lobo JMS, Pinto JF, Costa P. Compressed minitablets as a biphasic delivery system. Int J Pharm 2006; 323:93- 100. https://doi.org/10.1016/j.ijpharm.2006.05.063
8. Varshosaz J, Tavakoli N, Eram SA. Use of natural gums and cellulose derivatives in production of sustained release metoprolol tablets. Drug Del 2006; 13(2):113-119. https://doi.org/10.1080/10717540500313356

9. Onyechi JO, Okafo SE. Evaluation of carnauba wax in sustained release diclofenac sodium tablet formulation. J Chem Pharm Res 2016; 8(3):714-21.

10. Nart V, Beringhs AO, França MT, de Espíndola B, Pezzini BR, Stulzer HK. Carnauba wax as a promising excipient in melt granulation targeting the preparation of mini-tablets for sustained release of highly soluble drugs. Mater Sci Eng: C. 2017; 70:250-7. https://doi.org/10.1016/j.msec.2016.07.070

11. Gwen MJ, Joseph RR, Rhodes CT. Modern Pharmaceutics, Marcel Dekker, Inc., New York. 1996; 72(3):581.

12. Al Remawi M, Al-Akayleh F, Salem MS, Al Shami M, Badwan A Application of an excipient made from chitosan and xanthan gum as a single component for the controlled release of Ambroxol. J Excipients Food Chem 2016; 4(2):1087-9.

13. Jain KK. Drug delivery systems. 1st edition. Switzerland: Human Press; 2008. pp 1-51. https://doi.org/10.1007/978-1-59745210-6_1

14. Sakore S, Chakraborty B. Formulation and evaluation of enalapril maleate sustained release matrix tablets. Int J Pharm Biomed Res 2013; 4:21-6.

15. Udayakumar T, Suresh AG, Ubaidulla U. Formulation and evaluation of immediate and sustained release bilayered tablet with glibenclamide and metformin Hcl. Int J Res Dev Pharm Sci 2013; 2:337-43.

16. Shashidhar P, Vidya Sagar G, Srikanth G. Design and in-vitro evaluation of metformin hydrochloride (SR) and glimepiride (IR) as bilayered tablets. Int J Pharm Chem Sci 2013; 2:780-92.

17. Sridhar Babu G, Vijay Kumar D, Aishwarya M, Malathy PS, Redya Naik R. Formulation and in vitro characterization of sustained release matrix tablets of metformin Hcl. J Glob Trends Pharm Sci 2014; 5:2085-92.

18. Saluja V, Garg C. Once-daily sustained-release matrix tablets of metformin hydrochloride based on an enteric polymer and chitosan. J Pharm Educ Res 2013; 4:92-7.

19. Salsa T, Veiga F, Pina ME. Oral controlled-release dosage forms. i. cellulose ether polymers in hydrophilic matrices Drug Dev Ind Pharm. 1997; 23:929-938. https://doi.org/10.3109/03639049709148697 